\title{
EVALUASI PURNA HUNI (EPH) HOTEL SENYUM KOTA BATU PADA ASPEK TEMA “MEMORY AND ENTERTAINMENT"
}

\author{
Surjo Widodo ${ }^{1 *}$, Hery Budianto ${ }^{2}$, Nurhamdoko Boni ${ }^{3}$ \\ Mahasiswa Program Magister Arsitektur Universitas Merdeka Malang1, \\ Dosen Program Studi Magister Arsitektur ${ }^{2}$ \\ Dosen Program Studi Magister Arsitektur ${ }^{3}$ \\ *satria.lestari@yahoo.co.id
}

\begin{abstract}
ABSTRAK
Hotel Senyum adalah salah satu fasilitas di destinasi baru di dalam lingkungan Jawa Timur Park 3, di kota Batu. Hotel Senyum mengusung konsep memory and entertainment. Konsep Hotel Senyum ini memiliki keunikan yang mengarah kepada target wisata keluarga. Setiap lantainya memiliki tema-tema yang bernuansa berbeda dan diadaptasi dari beberapa negara, antara lain seperti: Jepang, Mexico, Cina, Maroko, Afrika, Eropa, Yunani dan Indonesia, sehingga menjadikan hotel ini menjadi sangat impresif. Melalui keunikan konsep memory and entertainment tersebut tulisan ini dimaksudkan untuk mengevaluasi kesesuaian tema dengan performansi fisik interior ruangnya menurut persepsi dan pandangan wisatawan sebagai pengguna. Penelitian ini bertujuan mengetahui sukses dan tidaknya hasil konsep asil rancangan tersebut, setelah Hotel Senyum ini satu tahun beroperasi. Penelitian dilakukan dengan menggunakan metode Evaluasi Pasca Huni (EPH). Metode EPH dilakukan guna menguji secara teknis dan fungsionalnya sebuah ruangan. Secara teknis berhubungan dengan kesesuaian antara standar teknikal dengan eksisting di lapangan, sedangkan fungsional mengacu pada kesesuaian aktivitas dengan ruang didalamnya. Analisis dilakukan untuk melihat indikasi keberhasilan dari keterkaitan tema-tema didalam sebuah perancangan pada interior kamar Hotel Senyum dengan persepsi suasana menurut responden. Hasil terkait dengan jenis kelamin (gender) didominasi kategori pria prosentase senilai $70 \%$, jumlah yang menginap dengan kategori sekali dominasi nilai prosentase $77 \%$, berkunjung dengan keluarga didominasi nilai prosentase $87 \%$, alasan menginap mencoba hotel baru mendominasi pada nilai prosentase $63 \%$, tema Kamar yang paling sering dikunjungi tema kamar Maroko dan tema kamar Jepang dengan dominasi masing-masing nilai prosentase $17 \%$, interior mencerminkan tema yang paling tinggi nilai prosentasenya $77 \%$ adalah kategori berhasil, elemen interior yang paling bagus dan memiliki paling tinggi nilai prosentasenya adalah kategori dekorasi dengan nilai $47 \%$, alasan memilih tema kamar coba hal baru yang tertinggi memiliki nilai prosentase $70 \%$, tingkat kepuasan dengan nilai prosentase $80 \%$ adalah kategori puas.
\end{abstract}

Kata kunci : memory and entertainment, tema desain interior, evaluasi purna huni (EPH)

\section{ABSTRACT}

Hotel Senyum is one of the facilities in a new destination within the Jawa Timur Park 3 neighborhood, in the city of Batu. Hotel Smile carries the concept of memory and entertainment. The concept of this Hotel Senyum is unique which leads to family tourism targets. Each floor has different nuanced themes adapted from several countries, such as: Japan, Mexico, China, Morocco, Africa, Europe, Greece and Indonesia, making this hotel very impressive. Through the uniqueness of the concept of memory and entertainment, this paper is intended to evaluate the suitability of the theme with the physical 
performance of the interior of the space according to the perceptions and views of tourists as users. This study aims to determine the success or failure of the results of the original design concept, after the Hotel Senyum has been operating for one year. The study was conducted using the PostOccupational Evaluation (EPH) method. The EPH method is used to test technically and functionally a room. Technically related to the suitability of technical standards with existing in the field, while functional refers to the suitability of the activity with the space in it. The analysis was carried out to see indications of the success of the interrelationship of themes in a design on the interior of the Hotel Senyum room with the perception of the atmosphere according to the respondent. The results related to gender are dominated by the male category, the percentage is $70 \%$, the number who stays in the single category is the percentage value is $77 \%$. The rooms most frequently visited are Moroccan theme rooms and Japanese room themes with a dominance of $17 \%$ each, the interior reflects the theme with the highest percentage value $77 \%$ is the successful category, the best interior element and has the highest percentage value is the decoration category with a value of $47 \%$, the reason for choosing the theme of the room to try new things is the highest percentage value of $70 \%$, the level of satisfaction with a percentage value of $80 \%$ is the satisfied category.

Keywords: memory and entertainment, interior design themes, after-occupancy evaluation (EPH

\section{PENDAHULUAN}

Membantu klien mendapatkan pengalaman terbaik dari proyek bangunan adalah alasan utama untuk mengevaluasi sebuah bangunan. Melalui Evaluai Purna Huni (EPH), inti kebutuhan klien dan penghuni dapat diketahui sehingga dapat menyempurnakan kinerja bangunan. Bagi arsitek EPH membantu mereka untuk mengetahui dan mendalami kesenjangan kinerja, yaitu bagaimana kinerja energi bangunan, kinerja pemrograman atau organisasi fungsi dan ruang, dan kinerja terukur aktual lainnya. Semakin banyak desainer, klien, dan anggota tim proyek lainnya belajar tentang bagaimana kinerja bangunan mereka saat digunakan, semakin baik kemungkinan bangunan mereka berikutnya untuk memenuhi kebutuhan kompleks klien dan penghuni. Mereka dapat menyelesaikan lingkaran pembelajaran yang baik.

Maksud dan tujuan tersebut menjadi pertimbangan penting untuk menggunakan EPH dalam mengevaluasi obyek fungsi hunian Hotel Senyum. Hotel senyum sebagai salah satu hotel yang termasuk baru dan merupakan salah satu tujuan wisata penginapan di kota Batu. Hotel ini berada di lingkungan area Jawa Timur Park 3, sebagai ikon baru dan merupakan salah satu destinasi wisata baru di kota Batu. Posisi dan letak Hotel Senyum yang strategis, yaitu di jalan poros utama Malang-Batu. Pertimbangan lain dalam penelitian ini adalah kesesuaiannya dengan misi Hotel Senyum untuk memberikan pelayanan terbaik bagi konsumen mereka. Potensi penggunaan fasilitas ini sangat besar terlihat dari letak lokasinya yang tampak jelas dari sisi jalan poros utama Malang - Batu dan memudahkan untuk diakses pengunjung dan wisatawan, baik yang dari arah kota Malang ataupun kota Batu. 
Hotel ini berdiri sejak bulan Desember 2018, dan mengangkat konsep "memory and entertainment" yang ramah untuk keluarga sebagai ciri khasnya. Sebuah upaya dimana konsep "memory and entertainment" ini mampu menciptakan dan mendukung fungsi dasar hotel sebagai wadah/tempat menginap. Hotel Senyum dituntut untuk mampu menyediakan fasilitas dan wadah yang nyaman dan menyenangkan tamu pengunjungnya. Konsep perancangan yang ditawarkan oleh Hotel Senyum tersebut diwujudkan melalui elemenelemen perancangan arsitektur, eksterior dan interiornya. Elemen-elemen perancangan tersebut ditujukan untuk menciptakan suatu kesan suasana dimana secara keseluruhan mampu merepresentasikan karakter atau ciri khas dari sebuah hotel. Dan hal seperti inilah yang nanti akan diinginkan oleh pihak hotel dan penerimaan tamu pengunjungnya.

Konsep "memory and entertainment" menjadi strategi untuk menciptakan keunikan dari Hotel Senyum. Setiap lantainya menerapkan tema-tema yang berbeda-beda sebagai representasi memory (kenangan) suasana dari berbagai negara antara lain Jepang, Mexico, Cina, Maroko, Afrika, Eropa, Yunani dan Indonesia sendiri sebagai tuan rumah. Sehingga menjadikan hotel ini memiliki suasana dan tampilan interiornya (ruang dalam) menjadi sangat impresif. Sebagai sebuah fasilitas pelayanan wisata Hotel Senyum memerlukan suatu langkah evaluasi untuk arah perbaikan dan pengembangan pelayanan itu sendiri.

Penelitian ini dilakukan untuk mengevaluasi kesesuaian tema dengan performansi fisik interior ruangnya menurut persepsi dan pandangan wisatawan sebagai pengguna. Penelitian ini bertujuan mengetahui sukses dan tidaknya hasil konsep asil rancangan tersebut, setelah Hotel Senyum ini satu tahun beroperasi. Penelitian dilakukan dengan menggunakan metode EPH. Metode EPH dilakukan guna menguji secara teknis dan fungsionalnya sebuah ruangan. Secara teknis berhubungan dengan kesesuaian antara standar teknikal dengan eksisting di lapangan, sedangkan fungsional mengacu pada kesesuaian aktivitas dengan ruang didalamnya.

\section{TINJAUAN PUSTAKA}

\section{Evaluasi Purna Huni (EPH)}

EPH dalam arsitektur memiliki makna investasi. Meskipun evaluasi pasca hunian dalam arsitektur sangat berharga, tidak semua arsitek khususnya menggunakannya. Sebagian alasan untuk menghindari evaluasi ini adalah karena biayanya lebih mahal, membutuhkan waktu untuk menyelesaikannya, dan membutuhkan banyak sumber daya. Beberapa arsitek juga khawatir menemukan kekurangan dalam desain bangunan. Meski demikian perusahaan arsitektur yang berpengalaman dan terpercaya justru bisa mengatasi tantangan dalam rangka memberikan pengalaman pengguna terbaik kepada klien mereka. 


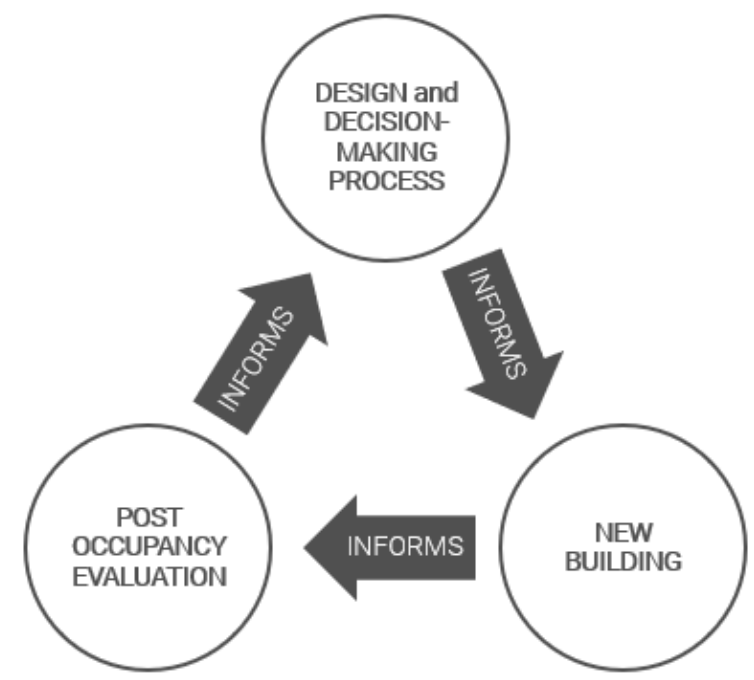

Gambar 1. Siklus informasi desain yang melibatkan EPH

EPH mempunyai beberapa pengertian kegiatan pengkajian kembali (evaluasi) terhadap bangunan-bangunan atau lingkungan binaan yang telah dihuni, dan didefinisikan sebagai pengkajian atau penilaian tingkat keberhasilan suatu bangunan dalam memberikan kepuasan dan dukungan kepada pengguna (user). Aspek kajian adalah nilai-nilai dan kebutuhannya, serta merupakan evaluasi terhadap tingkat kepuasan pengguna atas sebuah bangunan dengan mempelajari elemen-elemen bangunan tersebut setelah digunakan beberapa saat. (Sudibyo, 1989; Preiser dkk ,1998, Haryadi dan Slamet,1996).

EPH juga meliputi beberapa aspek, yaitu aspek teknis, aspek fungsional dan aspek perilaku (Choi \& Lee, 2018). Aspek teknis berhubungan dengan bagaimana penghuni bangunan mengharapkan bangunan huniannya aman dan nyaman. Hal tersebut akan berkaitan dengan aspek kondisi fisik bangunan yang menyangkut keamanan, kesehatan dan keselamatan dalam ruang terutama pada elemen-elemen interior bangunan (Setyawan dan Haryadi, 2010). Aspek Fungsional menyangkut aspek bangunan yang secara langsung mendukung kegiatan pemakai dengan segala atributnya. Perancangan bangunan yang menekankan fungsi, antara lain akan berpedoman pada kesesuaian antara area kegiatan dengan segala kegiatan yang berlangsung didalamnya. Salah satu hal yang merupakan bagian aspek fungsional adalah faktor manusia, terutama menyangkut segi-segi perancangan dan standar, yang dikaitkan dengan kesesuaian antara konfigurasi, material dan ukuran terhadap pemakainya (Sudibyo, 1989). Sementara aspek perilaku menghubungkan kegiatan pemakai dengan lingkungan fisiknya. Evaluasi perilaku ini adalah mengenai bagaimana psikologis penghuni bangunan dipengaruhi oleh rancangan bangunan, salah satunya dengan citra 
penghuni terhadap bangunan (Preiser, 1988). Sesuai pula apa yang dikatakan oleh Rabinowitz (dalam Syder, J.C., dan Catanese, A.J, 1988), bahwa tingkat kepuasan pengguna berkaitan dengan faktor fisik dan non fisik bangunan yang terkait aspek fungsional, teknis dan perilaku.

\section{Preferensi Pengguna pada Interior Hotel}

Persaingan pelayanan hotel semakin meningkat terutama di kawasan destinasi wisata. Penurunan tingkat okupansi hotel juga semakin mendorong layanan yang kompetitif. Pada situasi tersebut diperlukan suatu diferensiasi yang mampu menarik minat konsumen. Desain interior merupakan salah satu hasil produk hotel yang dapat dimanfaatkan sebagai pembentuk diferensiasi terhadap hotel pesaing. Meski demikian upaya identifikasi mengenai pengaruh dari desain interior hotel terhadap keputusan konsumen dalam memilih hotel masih belum banyak dilakukan. Mahendra (2016) dalam penelitiannya menegaskan bahwa strategi pemasaran hotel dapat dilakukan berdasarkan preferensi pemakai hotel. Hasil penelitiannya meunjukkan bahwa style modern-etnik pada sebuah interior hotel paling diminati oleh responden. Temuan tersebut mengindikasikan bahwa desain interior memiliki pengaruh terhadap ketertarikan konsumen, namun tidak sebesar atribut produk dan pengalaman terdahulu. Penelitian tersebut sekaligus mengindikasikan peranan memory konsumen dalam menentukan minat dan pilihan mereka.

Aspek teknis sangat berkaitan dengan elemen-elemen fisik sebagai implementasi konsep desain interiornya (Sanni-Anibire et al., 2016). Desain interior hotel sangat dibutuhkan dalam penataan ruang inap hotel agar tertarik berkunjung ke hotel. Kenyamanan tamu penghuni hotel sangat ditentukan oleh desain interior yang menyenangkan dan memuaskan. Desain interior hotel harus menarik dan unik agar tamu hotel terhindar dari kesan yang membosankan. Desain interior hotel dilakukan secara arsitektural, yang berarti mempunyai segi estetika yang tinggi tetapi harus memperhatikan faktor keamanan dan fungsional dari bangunan hotel tersebut. Desain interior memiliki seni rancang yang berkualitas agar suatu hotel dapat memiliki nilai estetika. Terdapat beberapa unsur yang membentuk desain interior diantaranya yaitu, ruang, hirarki, pencahayaan, tata suara, suhu udara, kualitas udara, style and fashion (gaya dan mode). Pemilihan konsep interior yang strategis bisa mengacu pada style dan fashion yang diminati oleh wisatawan sebagai pengguna hotel.

\section{METODE PENELITIAN}

Metode yang digunakan pada penelitian ini adalah metode deskriptif. Secara khusus menggunakan metode Evaluasi Purna Huni (EPH) atau Post Occupancy Evaluation (POE) yang sering digunakan untuk mengevaluasi bangunan setelah digunakan untuk beberapa waktu. POE (Post-Occupancy Evaluation) telah ada, dalam beberapa bentuk, sejak orang mulai menempati bangunan. Kaitannya dengan penilaian yang relatif sistematis tentang seberapa baik kinerja bangunan pada kriteria eksplisit lebih baru, tetapi telah ada setidaknya selama 
25 tahun. EPH adalah bentuk penelitian evaluasi yang dapat diterima secara akademis (Becker, 1989). EPH adalah alat diagnostik (pada dasarnya teknik klinis) dan penelitian perilaku lingkungan (dimaksudkan untuk membantu mengembangkan tradisi penelitian yang solid untuk memandu praktik arsitektur dan desain interior). Pada penelitian ini lebih menekankan pada tujuan yang kedua yaitu sebagai penelitian perilaku lingkungan. Secara khusus data dan analisis dilakukan pada unit-unit penelitian berupa tema-tema yang diterapkan pada desain interior unit hunian Hotel Senyum. Sebagaimana salah satu tujuan akhir dari EPH, penelitian ini diharapkan menghasilkan gambaran kepuasan konsumen terhadap desain-desain interior Hotel Senyum.

\section{HASIL PENELITIAN DAN PEMBAHASAN}

Hotel Senyum ini menghadirkan tema "memory and entertainment" dan menjadi konsep andalan dari arsitek perencananya. Evaluasi Pasca Huni (EPH) ini adalah bertujuan untuk mengetahui apakah perancangan pada Hotel Senyum ini sukses atau tidak terkait tema yang telah dipakai setelah lebih dari satu tahun beroperasi sejak Desember 2018. Fasilitas yang ada pada kamar Hotel Senyum, diantaranya yang berjumlah 206 kamar. Fasilitas pendukung lainnya, seperti jacuzy, gym, sauna, fitnes, panjat tebing, pool, bilyard, tenis meja. Sehingga secara kualitas suasana hotel ini cocok untuk wisata keluarga yang memiliki kelas deluxe, executive dan family room.

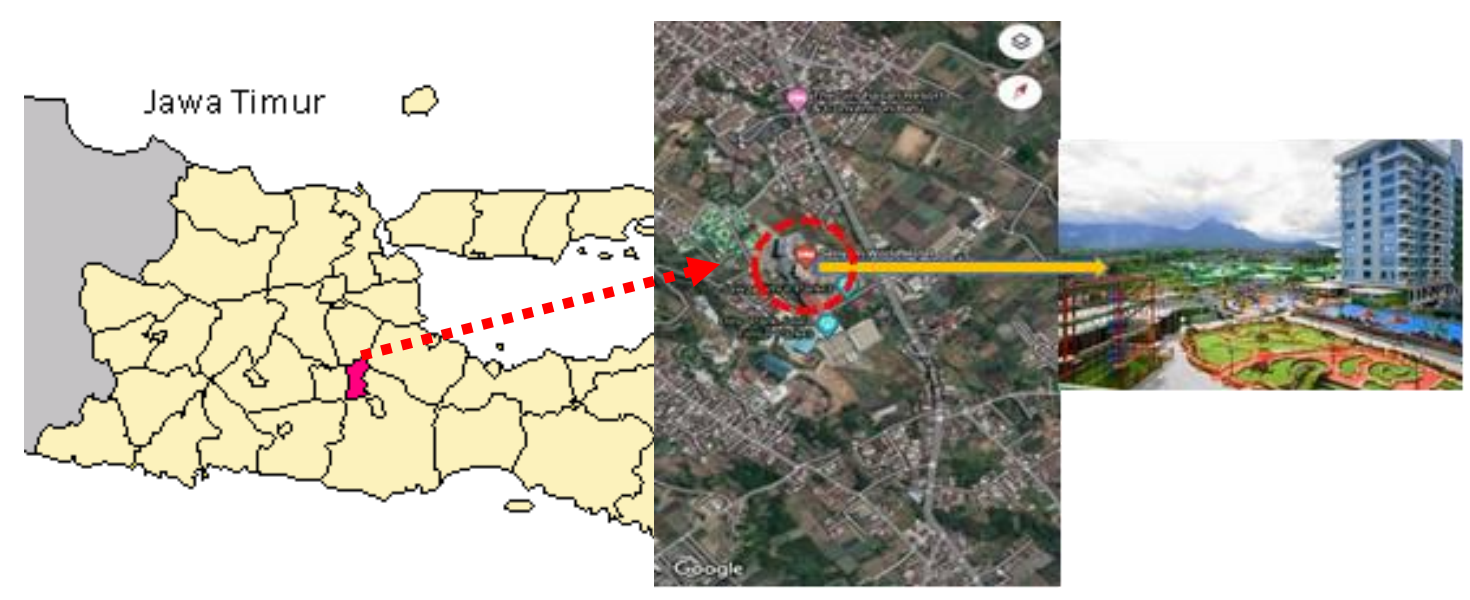

Gambar 2. Peta Lokasi Hotel Senyum Kota Batu

Mengacu pada beberapa interior tema kamar yang ada, telah dilakukan analisa terkait penelitian terhadap Hotel Senyum mencakup, antara lain: tema Indonesia, tema Cina, tema Maroko, tema Yunani, tema Jepang, tema Afrika dan tema Meksiko. Sampel kamar yang dipilih sejumlah 30 unit yang terbagi sebagaimana tabel 1.

Tabel 1. Tema dan jumlah sampel kamar 


\begin{tabular}{lll}
\hline Tema Maroko & 5 & $=5 / 30 \times 100 \%=17 \%$ \\
Tema Indonesia & 4 & $=4 / 30 \times 100 \%=13 \%$ \\
Tema Cina & 4 & $=4 / 30 \times 100 \%=13 \%$ \\
Tema Jepang & 5 & $=5 / 30 \times 100 \%=17 \%$ \\
Tema Afrika & 3 & $=3 / 30 \times 100 \%=10 \%$ \\
Tema Meksiko & 3 & $=3 / 30 \times 100 \%=10 \%$ \\
Tema Yunani & 4 & $=3 / 30 \times 100 \%=13 \%$ \\
\hline
\end{tabular}

Pada interior kamar dengan tema Indonesia (gambar 2) yang berukuran $36 \mathrm{~m} 2$, arsitek perancangnya berusaha mentransferkan dalam konsep rasa Indonesia yang berusaha diperlihatkan melalui sentuhan corak lantai, ornamen, dinding, dan lampu. Karakter dengan menggunakan pola batik tradisional Indonesia yang dikombinasikan dengan material modern. Aksen yang kuat adalah aksen Jawa dan Borneo., sehingga dalam konsep "memory and entertainment" ini berupaya menampilkan kesan yang dimunculkan adalah menunjukkan sebagai hal yang terkait dengan suasana yang "Welcome to Indonesia".

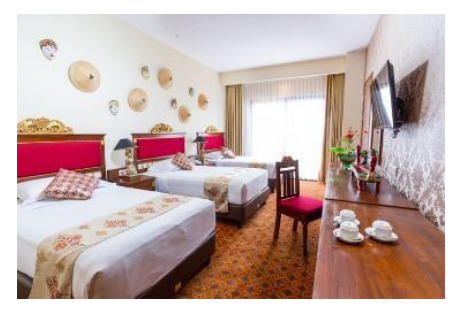

Gambar 2. Interior kamar tema Indonesia (surjo 2020)

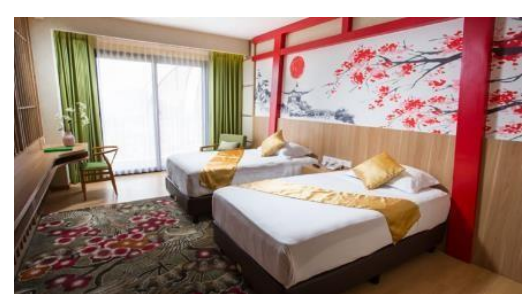

Gambar 3. Interior Kamar tema Jepang (surjo 2020)

Sedangkan pada gambar 3, adalah suasana view interior kamar dengan tema Jepang, dan konsep rasa Jepang ini berusaha dibangkitkan oleh sentuhan-sentuhan yang muncul pada ornament khas Jepang, lukisan Jepang ala perang yang mengapit gunung Fujiyama, dan lukisan matahari terbit. Pendekatan desain akses lorongpun diadopsi sama dengan suasana akses lorong yang ada di Jepang. Di atas tempat tidur ditempatkan lukisan jembatan Shinkyo.
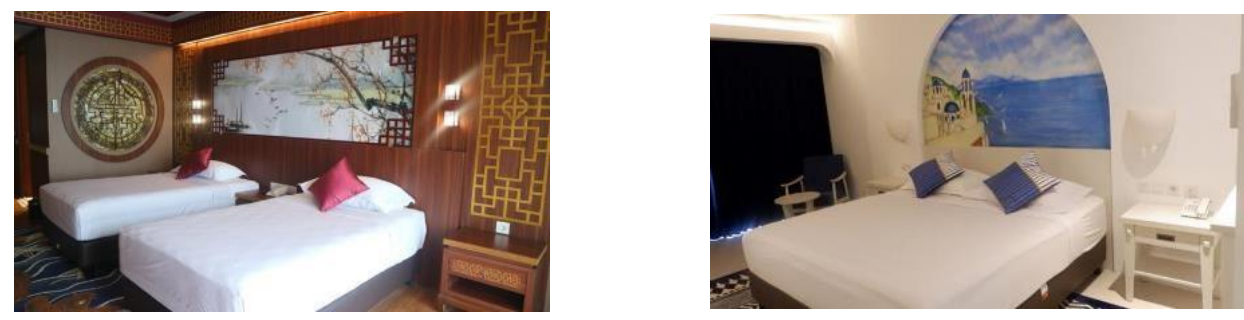
Suasana interior kamar dengan tema China (gambar 5), diperlihatkan penggunaan ornamen lantai dan ruangan didominasi warna merah dan merah tua (maroon). Dan dipadu dengan warna gelap, sehingga mampu memperlihatkan suasana yang kental ala oriental. Hiasan dinding dipadukan pula dan menggambarkan tema dari kekaisaran jaman kerajaan Cina masa lalu. Secara memori yang dimunculkan tersebut diharapkan mampu membuat tamu pengunjung merasakan seolah seperti berada pada suasana kamar di Cina.

Pada gambar 5, menunjukkan inerior kamar tema Yunani yang terkenal dengan suasana keindahan alam yang luar biasa. Hal terkait memori disini oleh sang parancang berupaya dikonsepkan dalam interior kamar. Dengan upaya meletakkan tema paduan antara lukisan pemandangan laut dan rumah di Yunani yang dijadikan sebagai backdrop pada area tempat tidur. Nuansa paduan warna yang dimunculkan dan digunakan adalah paduan anatara warna putih dan biru, paduan senada dengan motif dan warna pada lukisan.

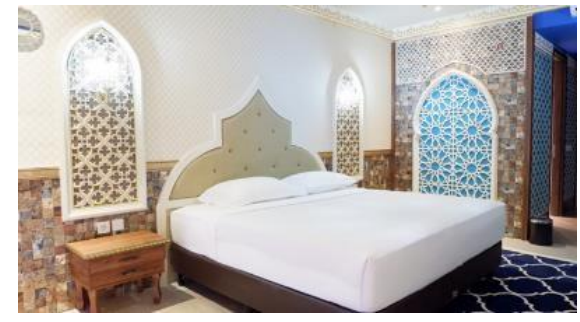

Gambar. 6. Interior kamar tema Maroko (surjo 2020)

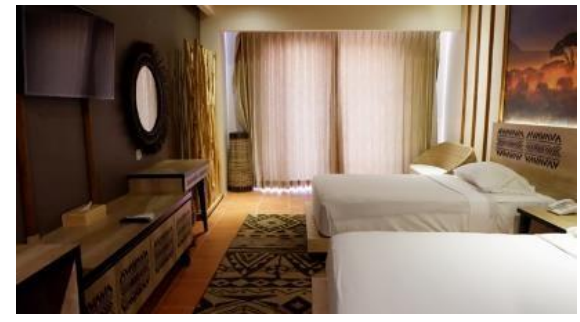

Gambar. 7. Interior kamar tema Afrika (surjo 2020)

Kebudayaan Maroko yang ditampilkan pada interior kamar (gambar 6) merupakan tata paduan campuran antara kebudayaan Arab, Eropa, dan Berber. Memunculkan gaya arsitektur Islam secara spesifik yang diadopsi sebagai paduan gaya konstruksi dan ornamen bangunan di Maroko selama berabad-abad. Ada tiga keunikan dari arsitektur gaya Maroko ini, diantaranya adalah bentuk minaret atau menara yang berbentuk persegi yang digunakan sebagai tempat untuk mengumandangkan adzan pada masjid. Kedua adalah penggunaan zallij (keramik mosaik dengan warna-warna cerah khas Maroko) untuk interior ruangan dan eksterior. Ketiga adalah Riad. Riad merupakan sebutan untuk rumah tinggal di Maroko dengan halaman terbuka di dalam rumah yang berbentuk persegi empat dengan air mancur di tengahnya. Bentuk arsitektur lengkungan runcing selalu digunakan dalam hampir seluruh aspek arsitektur Maroko. Dalam kamar tipe Maroko, ketiga aspek tersebut diadopsi, mulai dari penggunaan keramik mozaik, ornamen-ornamen runcing dan bentuk-bentuk menara.

Interior tema Afrika (gambar 7) yang terkenal dengan suasana gurun sahara dan hewanhewan liar menjadi tema interior Afrika. Backdrop dinding diberikan view suasana pemandangan gurun pasir dan binatang khas Afrika. Elemen dekorasi lainnya seperti motif tribal digunakan pula pada hiasan perabot ruangan dan serta pada motif karpet. 


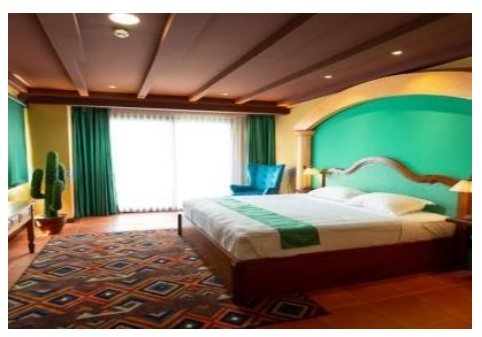

Gambar. 8. Kamar tema Meksiko (surjo 2020)

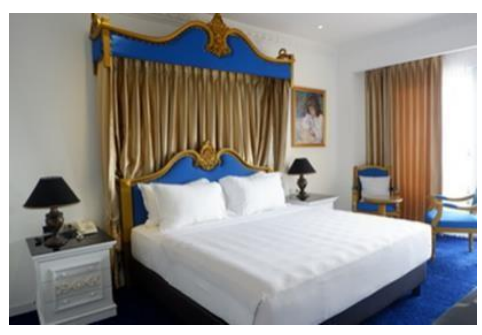

Gambar. 9. Kamar tema Eropa (surjo 2020)

Interior kamar dengan tema Mexico (gambar 8), terdapat paduan antara topi sombrero, tanaman kaktus, lorong berwarna hijau, mural bermotif Meksiko, gerbang besi ala Meksiko. Serta ditempatkan pula hiasan dinding yang diletakkan di bagian kanan dan kiri dari tempat tidur. Sedangkan pada interior kamar tema Eropa (gambar 9), ditempatkan beragam elemen-elemen dekorasi. Pola elemen dekorasi tidak semata-mata sebagai penghias interior saja, akan tetapi merupakan sebuah benda yang bernilai seni amat tinggi. Semisal tampilan dari dekorasi vas bunga antik, jam berukuran besar dengan bandul, pajangan dari marmer, lampu kristal berukuran besar yang digantungkan di tengah ruang keluarga. Model gaya masa lalu Eropa seperti gaya kerjaan Inggris di Eropa masa lalu, sehingga mampu memunculkan memori dan memiliki kesan kemewahan dan khas keluarga kerajaan Eropa.

\begin{tabular}{|c|c|c|c|}
\hline Uraian & Kategori & Frekwensi & $\begin{array}{c}\text { Persen } \\
\text { tase }\end{array}$ \\
\hline \multirow{2}{*}{ Jenis Kelamin } & Pria & 21 & $70 \%$ \\
\hline & Wanita & 9 & $30 \%$ \\
\hline \multirow{2}{*}{ Jumlah Menginap } & Sekali & 23 & $77 \%$ \\
\hline & Dua Kali/Lebih & 7 & $23 \%$ \\
\hline \multirow{2}{*}{ Berkunjung Dengan } & Keluarga & 26 & $87 \%$ \\
\hline & Sendiri & 4 & $13 \%$ \\
\hline \multirow{3}{*}{ Alasan Menginap } & Lokasi & 9 & $30 \%$ \\
\hline & Fasilitas & 2 & $7 \%$ \\
\hline & Coba Hotel Baru & 19 & $63 \%$ \\
\hline \multirow{8}{*}{$\begin{array}{l}\text { Tema Kamar Yang } \\
\text { Paling Sering } \\
\text { Dikunjungi }\end{array}$} & Afrika & 3 & $10 \%$ \\
\hline & China & 4 & $13 \%$ \\
\hline & Indonesia & 4 & $13 \%$ \\
\hline & Jepang & 5 & $17 \%$ \\
\hline & Maroko & 5 & $17 \%$ \\
\hline & Meksiko & 3 & $10 \%$ \\
\hline & Yunani & 4 & $13 \%$ \\
\hline & Abstain & 2 & $7 \%$ \\
\hline \multirow{2}{*}{$\begin{array}{l}\text { Alasan Memilih Tema } \\
\text { Kamar }\end{array}$} & Nostalgia & 5 & $17 \%$ \\
\hline & Coba Hal Baru & 21 & $70 \%$ \\
\hline
\end{tabular}




\begin{tabular}{|c|c|c|c|}
\hline & Lainnya & 4 & $13 \%$ \\
\hline \multirow{3}{*}{$\begin{array}{l}\text { Interior Mencerminkan } \\
\text { Tema }\end{array}$} & Berhasil & 23 & $77 \%$ \\
\hline & Belum & 5 & $17 \%$ \\
\hline & Abstain & 2 & $7 \%$ \\
\hline \multirow{4}{*}{$\begin{array}{l}\text { Elemen Interior Yang } \\
\text { Paling Bagus }\end{array}$} & Dekorasi & 14 & $47 \%$ \\
\hline & Dinding & 9 & $30 \%$ \\
\hline & Lantai & 1 & $3 \%$ \\
\hline & Perabot & 3 & $10 \%$ \\
\hline \multirow{6}{*}{$\begin{array}{l}\text { Elemen Interior Yang } \\
\text { Kurang }\end{array}$} & Dekorasi & 7 & $23 \%$ \\
\hline & Dinding & 4 & $13 \%$ \\
\hline & Lampu & 3 & $10 \%$ \\
\hline & Lantai & 6 & $20 \%$ \\
\hline & Perabot & 8 & $27 \%$ \\
\hline & Abstain & 2 & $7 \%$ \\
\hline \multirow{3}{*}{ Tingkat Kepuasan } & Puas & 24 & $80 \%$ \\
\hline & Kurang & 5 & $17 \%$ \\
\hline & Tidak & 1 & $3 \%$ \\
\hline
\end{tabular}

\section{SIMPULAN}

Berdasarkan hasil analisis dan pembahasan sebagaimana diuraikan di atas dapat disimpulkan bahwa:

- Kamar yang paling sering dikunjungi adalah kamar hunian yang kamar Maroko dan tema kamar Jepang. Kamar tersebut sekaligus menunjukkan penilaian paling bagus menurut pengunjung pada aspek interior dan elemen dekorasinya. Pemilihan tersebut juga menunjukkan preferensi pengunjung yang memiliki latar belakang tertentu yang berhubungan dengan tema, salah satunya adalah latar belakang agama, gender dan umur.

- Pengunjung memiliki kecenderungan memberikan penilaian kepuasan tinggi yang didasarkan pada alasan pemilihan kamar untuk mencoba tema kamar baru.

Hasil penelitian ini memberikan rekomendasi sebagai berikut:

- Perlu dilakukan penelitian lebih lanjut tentang preferensi pengunjung terhadap kesan dan style dari kamar yang berhubungan dengan teknis perawatan, tingkat hospitality baik yang berhubungan langsung dengan arsitek untuk pengembangan desain tata ruang maupun bagi pengelola dalam hal kemudahan maintenance.

\section{REFERENSI}

Becker, F. (1989). Post-Occupancy Evaluation: Research Paradigm or Diagnostic Tool. In W. F. E. Preiser (Ed.), Building Evaluation (pp. 127-134). Springer US. 
https://doi.org/10.1007/978-1-4899-3722-3_10Ching, F.D.K. (1996). Ilustrasi Desain Interior. Jakarta: Erlangga.

Ching, F.D.K. (2002). Architecture, Space and Order. New York: Maxmillan Publishing Company.

Choi, J.-H., \& Lee, K. (2018). Investigation of the feasibility of POE methodology for a modern commercial office building. https://doi.org/10.1016/J.BUILDENV.2018.07.049

Hartman, T. (1987). The Color Code. California.

Lawson, F. (1988). Hotels \& Resorts Planning, Design and Refurbishment. Oxford: Butterworth Architecture.

Nurhayati. (2004). Penataan Tanaman di Rumah Tinggal. Jakarta: Gramedia.

Preiser, W.F.E. (1989). Building Evaluation. New York: Plenum Press.

Sanni-Anibire, M. O., Hassanain, M., \& Al-Hammad, A.-M. (2016). Post-Occupancy Evaluation of Housing Facilities: Overview and Summary of Methods. Undefined. https://www.semanticscholar.org/paper/Investigation-of-the-feasibility-of-POEmethodology-Choi-Lee/4bc49908ffae180a00d7d19341da2411f76e59af

Setiawan, B. dan Haryadi. (2010). Arsitektur, Lingkungan dan Perilaku. Yogyakarta: Gadjah Mada University Press.

Snyder, J.C., dan Catanese, A.J., (1988). Pengantar Arsitektur. Jakarta: Erlangga.

Sudibyo, S. (1989). Aspek Fungsi dan Teknik Post Occupancy Evaluation dan Beberapa Metodologi Penelitian. Dalam Seminar Pengembangan Metodologi Post Occupancy Evaluation. Jakarta: Trisakti.

Sulastiyono, A. (1999). Manajemen Penyelenggaraan Hotel. Bandung: Alfabeta.

Suptandar, J.P. (1991). Desain Interior: Pengantar Merencana Interior untuk Mahasiswa Desain dan Arsitektur. Jakarta: Djambatan. 